\title{
Causal relations on a cline of explicitness: an SFL perspective
}

\author{
Waleed Othman
}

Correspondence:

OTHMANWALEED@GMAIL.COM

University of Petra, Amman, Jordan

\begin{abstract}
This paper is an attempt to categorize cause-effect relations in English in terms of explicitness on the basis of realisation and choice. Specifically, making use of SFL's concept of grammatical metaphor and the dimension of delicacy, I suggest that cause-effect relations can be placed on a cline with respect to how explicitly they encode logico-semantic meaning.
\end{abstract}

Keywords: Cause, SFL, Choice, Grammatical metaphor, Delicacy

\section{Introduction}

The concept of causality has been subject to studies in numerous fields, such as philosophy, science, and linguistics. As a philosophical concept, causality is an epistemological phenomenon relating to nature and justification of causal knowledge (Bulman 1977). In cognitive linguistics, where causality relations have received abundant attention, the concept is defined as a psychological tool of humans to understand the word independently of language, and it is one of the principles involved in the construction of the human mental model of reality (Neeleman and van de Koot 2012). Quinton $(1977,92)$ defines causality in less abstract terms as "the relation between two events or states of affairs in which one brings about or produces the other". For the purposes of this paper, we find the classificatory definition provided by SFL more relevant: It is a logico-semantic relationship of enhancement that shows the reason, result, or purpose of an event or action (Halliday and Matthiessen 2014).

Also relevant about SFL's treatment of causal relations is their general classification in terms of the domain of realisation, which helps avoid restricting the representation of causal meaning to specific linguistic features, such as verbal markers of cause and effect. In SFL, causal relations can be markedly and un-markedly realised experientially (in clause simplexes), logically (in clause complexes), and textually (in cohesive sequences). These three domains of realisation are illustrated in the next section. In this paper, I argue that different realisations of causal relations within and across different domains can vary in terms of how explicitly they encode the logico-semantic relation of cause. The argument is based on objective, measurable criteria represented by the parameters of realisational congruency and delicacy (see Section 3).

(c) The Author(s). 2020 Open Access This article is licensed under a Creative Commons Attribution 4.0 International License, which permits use, sharing, adaptation, distribution and reproduction in any medium or format, as long as you give appropriate credit to the original author(s) and the source, provide a link to the Creative Commons licence, and indicate if changes were made. The images or other third party material in this article are included in the article's Creative Commons licence, unless indicated otherwise in a credit line to the material. If material is not included in the article's Creative Commons licence and your intended use is not permitted by statutory regulation or exceeds the permitted use, you will need to obtain permission directly from the copyright holder. To view a copy of this licence, visit http://creativecommons.org/licenses/by/4.0/. 
That different realisations are different in the meaning they encode is a basic tenet in SFL. SFL views language as a system of meaning potential (Halliday 1978), while SFL itself is "a theory of meaning as choice" (Halliday 1992, 15). From this perspective, a text is a meaning-making activity, and the rich architecture of SFL provides the basis for a systematic investigation of the actual choices made by an author as well as the ones that could have been made (Thompson and Muntigl 2008). According to SFL, different choices, or different utterances, express different kinds of meanings. For example, English has several grammatical resources for realising cause-effect relations, which can be encoded in a variety of grammatical constructions. Such alternative lexicogrammatical realisations represent different kinds of meanings of the same experience. Whenever we need to express a certain experience, we choose to talk about it in a specific way and at the same time avoid other realisations. The choices we make are of course not arbitrary; rather, they reflect the intentions or purposes of the discourse, as well as norms and conventions related to context, register, or culture. Consequently, all choices are meaningful (Halliday 1971), and language users can make choices that are suitable for social contexts. As Hasan $(1984,105)$ puts it, "ways of saying are ways of meaning". That is, meanings are realised through forms.

SFL looks at language as a system of various strata: semantics, lexicogrammar, and phonology/graphology. These strata are linked through realisation: semantics (the system of meaning) is realised by lexicogrammar, and lexicogrammar is realised by phonology (the system of sounding, in the case of oral communication) or graphology (in the case of written communication). In addition to semantics and lexicogrammar, the notion of context assumes a very important role in SFL theory. Because the instantiation of meaning is determined by situational contexts, context is regarded as a stratum on its own. In fact, language use is treated in SFL as being inherently dependent on context, thus giving rise to patterns of language according to use in context, i.e. registers.

In this paper, no attempt is made to look at causal relations in terms of instantiation, i.e. with respect to register. The model proposed here looks at individual instances of cause construal in terms of the systemic choices available to the author, particularly with regard to realisational congruency and delicacy. Thus, an individual cause-effect encoding is regarded more explicit than other agnates if it realises meaning in more explicit lexicogrammar, i.e. by including more content or increasing congruency and/or delicacy. On the other hand, an individual cause-effect encoding is regarded less explicit than other agnates if it realises meaning in less explicit lexicogrammar, i.e. by including less content or decreasing congruency and/or delicacy.

However, since explicitness is a relative feature that can describe not only individual constructions, but also whole texts, the model can be expanded to include instantiation as a global parameter. So at the text level, we can speak of a degree or level of explicitness of the text that results from the entirety of relevant realisations measured against registerial conventions.

The paper is organised as follows. Section 2 illustrates congruent and incongruent cause construal in English experientially, logically, and textually. This is followed in Section 3 by a detailed illustration of the criteria used to describe expressions of cause-effect relations and locate them on the cline. In Section 4, I explain how the parameters are applied in classifying causal constructions according to their level of explicitness. 


\section{Causal relations: domains of realisation}

\section{The clause simplex: experiential cause construal}

The clause simplex corresponds to the experiential metafunction in SFL. Experientially, "the clause construes a quantum of change in the flow of events as a figure, or a representation of experience in the form of a configuration, consisting of a Process, Participants taking part in this Process, and associated Circumstances" (Halliday and Matthiessen 1999, 52). The attendant Circumstances, if there are any, expand the clause by means of elaboration, extension, or enhancement. Cause, the focus of this paper, belongs to the enhancement type of expansion. Grammatical opportunities for construing cause experientially, that is, at the rank of the clause simplex, include the following realisations:

\section{As a circumstance}

Cause is marked by a preposition or an adverbial expression, e.g. She died due to ignorance of the rules.

\section{In the process}

Cause is marked by the verb, e.g. Her ignorance of the rules caused her death.

\section{In a participant}

Cause is marked by the head noun in a nominal group, e.g. The cause of her death was her ignorance of the rules.

The clause complex: logical cause construal

The realisation of causal relations in clause complexes corresponds to the logical metafunction in SFL. In a clause complex, two figures are realised in a sequence. Specifically, two clause simplexes are linked or bound by a Relator. In SFL, the Relators used in such clause complexes are referred to as structural conjunctions. In this paper, I will refer to them simply as conjunctions. A distinction can be made between paratactic clause complex and hypotactic clause complex:

\section{Paratactic clause complex}

Two clauses of equal semantic status construe one figure each, with the latter providing enhancing information about the cause or effect of the first. The two clauses are related by a paratactic conjunction, e.g. She didn't know the rules, so she died.

\section{Hypotactic clause complex}

In this case the two clauses are of unequal semantic status: one provides the cause of the other. The Relator binding the two clauses is a hypotactic conjunction, e.g. Because she didn't know the rules, she died.

\section{Non-finite hypotactic clause complex}

The cause Relator is left implicit as a result of using the non-finite form of the verb in the secondary clause, e.g. Not knowing the rules, she died. 
The cohesive sequence: textual cause construal

The realisation of causal relations in cohesive sequences corresponds to the textual metafunction in SFL. It is a textual relationship that holds between two clauses or longer stretches of discourse. This may be achieved with or without the use of conjunctives, such as therefore, consequently, hence, etc. (Halliday and Matthiessen 2014, 439440). The Relators used in such cohesive sequences are referred to as cohesive/textual conjunctives, or conjunctive adjuncts. In this paper, I will refer to them as conjunctives. Manifestations of cohesive sequences include the following.

\section{Zero conjunctive}

Two clauses or stretches of text are juxtaposed without a conjunctive, e.g. She didn't know the rules. She died.

\section{Use of a conjunctive}

Two clauses or stretches of text are tied with a conjunctive, e.g. She didn't know the rules. Consequently, she died.

\section{Congruent vs. incongruent realisations}

As with almost any lexicogrammatical structure, causal constructions can be either unmarked or marked. Unmarked constructions are referred to as congruent realisations of the semantic categories and lexicogrammatical categories. On the other hand, marked realisations are referred to as incongruent mappings, or grammatical metaphor.

In SFL, anything that can be construed as part of human experience is a phenomenon. This is the most general experiential (semantic) category, of which there are three orders of complexity (cf. Halliday and Matthiessen 1999).

Figure: This is a configurational phenomenon that consists of elements. This semantic category represents experience as a configuration of a Process, the Participants that take part in the Process, and associated Participants (e.g. he cannot come to the party).

Element: This is an elemental phenomenon. The three kinds of elements in a figure are the Process (being, e.g. is; doing, e.g. walk; sensing, e.g. see; saying, e.g. contend), Participant (a thing, e.g. man, recipe; or a quality, e.g. partly cloudy), and Circumstance (time, e.g. today; manner, e.g. carefully; extent, e.g. for 15 min; etc.). A fourth type of element is the Relator (e.g. so, because), which functions between figures in sequences as a construal of logico-semantic relations.

Sequence: This is a complex phenomenon that consists of figures related temporally, causally, etc. One of the figures in a pair of figures may either expand the other (e.g. he cannot come to the party, but he will send his children; he cannot come to the party because he has work to do) or project it (e.g. I think he cannot come to the party; he says, "I cannot come to the party").

Thus, in the congruent (i.e. typical) mode, the resources for construing experience are those shown in Table 1:

However, semantic categories and lexicogrammatical categories are not in a one-toone relationship. Other mappings are possible; sequences, figures and elements as semantic resources for construing experience may be realised incongruently (metaphorically). That is, a given semantics can be grammaticalised in ways other than the 
Table 1 The congruent lexicogrammatical realisations of semantic categories

\begin{tabular}{ll}
\hline Semantics & Lexicogrammar \\
\hline sequence & clause complex \\
figure & clause simplex \\
element & \\
$\quad$ Participant & nominal group \\
Process & verbal group \\
Circumstance & prepositional phrase/adverbial group \\
Relator & conjunctions \\
\hline
\end{tabular}

congruent way. Incongruent expressions are referred to as grammatical metaphor, or incongruent mappings/realisations. Consider the following example (from Halliday and Matthiessen 1999, 227, also discussed in Teich 2003).

A: Smith et al. have shown that [if one takes alcohol one's brain rapidly becomes dull].

B: [Alcohol's rapid dulling effect on the brain] has also been observed by other researchers in the field (Teich 2003, 46; underlined parts in the original are rendered here in brackets).

The two bracketed parts in the text above grammaticalise the same ideational meaning in different lexicogrammar. Semantically the first is a sequence while the latter is an element. In terms of lexicogrammar, while the first is a clause complex, the latter is a nominal group. Several shifts are involved in this move from clause complex to nominal group, or from a sequence to an element; for example, the conjunction if, functioning as a logico-semantic Relator between two clauses, has been replaced by the noun effect, which functions as Head in the nominal group. Typically, such shifts involve loss of information, which can be tested by rewording variant $\mathrm{B}$ as variant $\mathrm{A}$, the former is ambiguous as to the logico-semantic relation (potentially referring to either cause/condition or location/time). In other words, variant B, being worded at a lower rank is less explicit than variant A (cf. Halliday and Matthiessen 1999, 227-231).

Halliday and Matthiessen (1999) place congruent and incongruent mappings of a given semantics on a cline, rather than as symmetrically related variants, thus, no simple dichotomy is maintained between 'literal' and 'metaphorical', but rather a continuum with the least metaphorical at one pole and the most metaphorical at the other pole. In general, "the variant that contains most information, or the least ambiguous one, is the congruent variant; the others belong to the set of metaphorical options" (Teich 2003, 47).

In this paper an attempt is made to place causal constructions on a cline with respect to their level of explicitness. To this end, I draw upon SFL's notions of choice, realisational congruency and delicacy to propose a model for a micro-level analysis of causal constructions that is aimed at determining their level of explicitness. Constructions are looked at as choices, or as different mappings within the systemic potential of the language. Thus, the current model classifies causal instances not only based on how much of the content or meaning is realised but also on how they compare with alternative realisations in terms of congruency and delicacy. A detailed illustration of the criteria used to describe expressions of cause-effect relations and locate them on the cline is 
presented in the next section. This is followed, in Section 4, with an explanation of how the criteria are applied in classifying causal constructions according to their level of explicitness.

\section{Explicitness criteria for causal constructions}

To place causal constructions on a cline of explicitness, I consider them in terms of realisational congruency and delicacy. Realisational congruency is classed at three different levels based on the metafunction involved.

\section{Experiential congruency}

The experientially congruent construal of a figure, or a quantum of change, is a clause simplex, as in she didn't know the rules. If we need to congruently expand on this figure with another quantum of change, we will then add another clause simplex. For example, she didn't know the rules, so she died, or she died because she didn't know the rules. In this case, we have a sequence of two quanta of change realised congruently in the form of a clause complex, in which the secondary clause logically enhances the primary clause. In addition to these congruent realisations by means of logical enhancement, we can also encode the same sequence in the form of a cohesive sequence with a conjunctive, e.g. she didn't know the rules. Consequently, she died; or without a conjunctive, e.g. she died. She didn't know the rules. Because each clause in the examples in this paragraph encodes a figure, we say that they all are experientially congruent realisations of the logico-semantic relation of cause.

So, at clause level, the congruent realisation of the semantic category of figure is the clause, and that of the semantic category of sequence is the clause complex or the cohesive sequence. We can also speak of experiential congruency when describing the elements within the clause transitivity. In she didn't know the rules, so she died, the two Participants in the primary clause are congruently realised by nominal groups (she, the rules), and the Process is congruently realised by a verbal group (didn't know). Thus, the primary clause as a whole is realised congruently because it is a construal of one figure. The same is true of the secondary clause (she died). The two clauses together make a sequence, which is congruently realised by a clause complex.

However, a single clause can often condense two quanta of change (i.e. events or goings-on). When one of the two figures, which represents the cause or the effect, is realised by a prepositional phrase serving as a Circumstance in the clause configuration, the clause is no longer regarded as a congruent experiential realisation. In other words, the semantic categories are not realised using congruent lexicogrammatical resources. In SFL, a prepositional phrase functioning as a Circumstance in a clause simplex is termed a minor Process. According to Halliday and Matthiessen $(1999,329)$, the "prepositional phrase can be interpreted as a shrunken clause, in which the preposition serves as a 'minor Process', interpreted as a kind of mini-verb, and the nominal group as a Participant in this minor Process", e.g. "the delay was because of [i.e. caused by] a strike". The following examples illustrate this further.

Her death was due to ignorance of the rules.

She died because she didn't know the rules. 
In the first of these examples, two figures are condensed in a clause simplex (dying and being ignorant). The second example expresses the same figures in a clause complex, i.e. a sequence rather than a single figure. Because of this realisational incongruency of the clause simplex in the first example, we could say that it is less explicit than the clause complex example. By the same token, we could say that the clause simplex is also less explicit than a cohesive sequence with a conjunctive, which is also a congruent lexicogrammatical realisation of the semantics of the cause-effect relationship (e.g. She didn't know the rules. Consequently, she died).

The other two experiential realisations of cause, by means of a Participant or the Process itself, can also be seen as cases of condensed information, again because two figures are encoded in a single clause. Consider her ignorance of the rules caused her death, or the cause of her death was her ignorance of the rules. Based on this experiential incongruency, i.e. the realisation of the semantic category of sequence by means of a clause simplex, we could reach the same conclusion regarding the level of explicitness. That is, a clause simplex construing a cause-effect relationship that is marked by the Process or a Participant is less explicit than a clause complex or a cohesive sequence that encodes the same cause-effect relationship.

Thus, the parameter of experiential congruency, which denotes realisation of semantic categories by typical lexicogrammar, can be helpful for comparing the level of explicitness of a clause simplex, a clause complex, and a cohesive sequence that all construe the same experience. The general conclusion, from the perspective of experiential congruency, is that a clause simplex with two condensed figures is less congruent and therefore also less explicit than a clause complex or a cohesive sequence that construes the same experience. However, things are not so straightforward, and we cannot simply claim or generalise that a clause simplex is less explicit than a clause complex. This becomes apparent when explicitness is examined from perspectives other than that of experiential congruency. To explain this point, the following subsections examine manifestations of cause-effect from the perspective of the cause marker or Relator. For this analysis, three relevant parameters can be identified: logical congruency, textual congruency, and delicacy.

\section{Logical congruency}

From a logical perspective, the congruent realisation of a cause Relator is a structural conjunction (e.g. because, since, as, for, so). In this sense, conjunctions in clause complexes are the only logically congruent realisations of cause Relators. Based on this, we could say, pro tem, that a clause complex is logically more explicit than a clause simplex, both construing the same cause relation. In this sense, both hypotactically related clauses and paratactically related clauses represent a congruent mode of realising logico-semantic relations not only (1) since they express both parts of the relation each in a single clause (and are therefore experientially congruent) but also (2) because they explicitly mark the logico-semantic relation with a conjunction, and are thus logically congruent (See, for example, Martin 1992; Halliday and Matthiessen 1999). In she died because she didn't know the rules, the primary and secondary clauses each construe a figure, so both are experientially congruent, and the cause relation is marked explicitly by because, making this construal logically congruent. 
Textual congruency

From a textual perspective, the congruent realisation of a cause Relator is a nonstructural conjunction (i.e. a conjunctive, e.g. therefore, thus, hence, as a result, consequently). In this sense, because conjunctives function in cohesive sequences, they are textually congruent realisations of cause Relators. Based on this, we could say that a cohesive sequence is textually more explicit than a clause simplex or clause complex, all construing the same causal relation. As with clause complexes, cohesive sequences represent two congruent modes of realisation: they not only (1) express both parts of the relation each in a single clause (and are therefore experientially congruent) but also (2) explicitly mark the relation with a conjunctive, and are therefore textually congruent. Moreover, while conjunctions only indicate the logical relationship between clauses, conjunctives (3) realise logical relations in the semantics (as modelled in $\mathrm{RST}^{1}$ ), in addition to their function as discourse organisers (see for example Martin 1992; Thompson 1996). For example, in she didn't know the rules. Consequently, she died, there are two figures that are realised in two clauses and the explicit cause marker consequently, which is functional both logically and textually.

The two parameters (logical and textual congruency) are then useful when comparing clause complexes with cohesive sequences, provided that both have explicit cause Relators (i.e. conjunctions or conjunctives). A cohesive sequence is more explicit than a clause complex because the latter realises only two of the three functions that the former realises. This was illustrated in the two examples in the last two paragraphs above. Often though there is a need to compare realisations at the same rank, rather than across ranks as already explained. Clause simplexes are not always equally explicit or implicit, nor are clause complexes or cohesive sequences. To address this, we need to look at the Relator from the perspective of delicacy.

\section{Delicacy}

Delicacy is the organising principle that orders paradigmatic options on a system network from the least to the most delicate, i.e. as a range of possible type-subtype relations in the paradigmatic description of a particular unit (Teich 2003, 50). For example, the system of Process type can be extended in delicacy to include the subtypes of mental Processes: emotive (e.g. love), cognitive (e.g. believe), desiderative (e.g. want), and perceptive (e.g. notice). More specifically, in the context of cause, the cline of delicacy extends from grammar to lexis, with grammar being the least delicate and lexis the most delicate (Halliday and Matthiessen 1999, 2004, 2014). In other words, structural meanings, in comparison with lexical meanings, are more generalised, have less explicit content, and are in these senses less explicit (Steiner, personal communications; Hunston, personal communications. One reason why the preposition through or the conjunction so are less explicit than the conjunctive the result of this or the conjunction leading to is that the former are structural and the latter are non-structural, i.e. the former are part of the morphosyntax of a language and the latter more part of the lexis.

${ }^{1}$ RST (Rhetorical Structure Theory) is a logical semantic system for developing text by means of the rhetorical, or logico-semantic, relations of projection and expansion. (Matthiessen et al. 2010) 
Moreover, words like so and through can have multiple meanings and/or functions, unlike phrases like the result of and leading to.

\section{Applying the parameters}

This section provides examples of cause in clause simplexes (Set 1, presented in Table 2), clause complexes (Set 2, presented in Table 3) and cohesive sequences (Set 3, presented in Table 4) and assesses each example against the four parameters of explicitness outlined above (experiential congruency, logical congruency, textual congruency, and delicacy). The parameters are assessed as being satisfied $(\boldsymbol{})$ or not satisfied (X); in the case of experiential congruency, this is done separately for each figure. The parameters of logical and textual congruency are only looked at when comparing clause complexes with cohesive sequences. This is because logical congruency is true of both clause complexes and cohesive sequences, while textual congruency is satisfied only in cohesive sequences, which makes them more explicit (see below). The examples in this section are all constructed from a clause taken from DeLorenzo 1993.

\section{Set 1: clause simplexes}

All four examples in Set 1 (Table 2) are clause simplexes, and they are all manifestations of the same cause-effect relationship. They are incongruent experientially, logically, and textually. Experientially, they are all incongruent because in each, two quanta of change, or figures, are encoded in a single clause simplex. They are logically and textually incongruent because they lack a logical or a textual Relator. The difference lies in delicacy. Starting with (1) and (2), both construing cause in a prepositional phrase, we can say that (2) is more explicit than (1). This is because the complex preposition in (2) includes a lexical item (e.g. result) that helps us detect the semantic content of the preposition. In other words, it is closer to the lexical end of the cline of delicacy. Structural Relators that include such lexical items are henceforth referred to as semi-lexical Relators. On the other hand, simple prepositions, such as through, lack such lexical traces and therefore have more generalised meanings, which renders them more difficult to comprehend by the reader. Bordet and Jamet $(2010,6)$ quote Borillo (2001) as saying that lexical items help us detect the semantic content in complex prepositions. This point can be further supported by reference to cognitive linguistics. In a study of

Table 2 Clause simplexes

\begin{tabular}{|c|c|c|c|c|}
\hline $\begin{array}{l}\text { Experiential } \\
\text { congruency }\end{array}$ & $\begin{array}{l}\text { Logical } \\
\text { congruency }\end{array}$ & $\begin{array}{l}\text { Textual } \\
\text { congruency }\end{array}$ & Delicacy & Clause simplex \\
\hline$\sqrt{5}$ & $x$ & $x$ & $x$ & $\begin{array}{l}\text { (1) The traditional approach has consistently failed through } \\
\text { ignorance of the realities of history and material } \\
\text { development. }\end{array}$ \\
\hline$\checkmark \times$ & $x$ & $x$ & $\checkmark$ & $\begin{array}{l}\text { (2) The traditional approach has consistently failed due to/ } \\
\text { because of/owing to/as a result of ignorance of the } \\
\text { realities of history and material development. }\end{array}$ \\
\hline$x \times$ & $x$ & $x$ & $\checkmark$ & $\begin{array}{l}\text { (3) The traditional approach consistent failure was caused } \\
\text { by ignorance of the realities of history and material } \\
\text { development. }\end{array}$ \\
\hline$x \times$ & $x$ & $x$ & $\checkmark$ & $\begin{array}{l}\text { (4) The cause of the consistent failure of the traditional } \\
\text { approach was ignorance of the realities of history and } \\
\text { material development. }\end{array}$ \\
\hline
\end{tabular}


Table 3 Clause complexes

\begin{tabular}{|c|c|c|c|c|}
\hline $\begin{array}{l}\text { Experiential } \\
\text { congruency }\end{array}$ & $\begin{array}{l}\text { Logical } \\
\text { congruency }\end{array}$ & $\begin{array}{l}\text { Textual } \\
\text { congruency }\end{array}$ & Delicacy & Clause complex \\
\hline$\checkmark \checkmark$ & $x$ & $x$ & $x$ & $\begin{array}{l}\text { (5) Having been ignorant of the realities of history and } \\
\text { material development, the traditional approach consistently } \\
\text { failed. }\end{array}$ \\
\hline$\checkmark \checkmark$ & $x$ & $x$ & $x$ & $\begin{array}{l}\text { 6) The traditional approach has ignored the realities of } \\
\text { history and material development, and it has consistently } \\
\text { failed. }\end{array}$ \\
\hline$\checkmark \checkmark$ & $\checkmark$ & $x$ & $x$ & $\begin{array}{l}\text { (7a) The traditional approach has ignored the realities of } \\
\text { history and material development, (and) so it has } \\
\text { consistently failed. }\end{array}$ \\
\hline$\checkmark \checkmark$ & $\checkmark$ & $x$ & $x$ & $\begin{array}{l}\text { (7b) The traditional approach has consistently failed, for it } \\
\text { has ignored the realities of history and material } \\
\text { development. }\end{array}$ \\
\hline$\checkmark \checkmark$ & $\checkmark$ & $x$ & $x$ & $\begin{array}{l}\text { (7c) Since/As it has ignored the realities of history and } \\
\text { material development, the traditional approach consistently } \\
\text { failed. }\end{array}$ \\
\hline$\checkmark \checkmark$ & $\checkmark$ & $x$ & $\checkmark$ & $\begin{array}{l}\text { (8a) Because it has ignored the realities of history and } \\
\text { material development, the traditional approach consistently } \\
\text { failed. }\end{array}$ \\
\hline$\checkmark x$ & $x$ & $x$ & $\checkmark$ & $\begin{array}{l}\text { (8b) The traditional approach has ignored the realities of } \\
\text { history and material development, resulting in/leading to/ } \\
\text { which resulted in its consistent failure. }\end{array}$ \\
\hline$\checkmark \checkmark$ & $\checkmark$ & $x$ & $\checkmark$ & $\begin{array}{l}\text { (8c) The traditional approach has ignored the realities of } \\
\text { history and material development, with the result that it } \\
\text { has consistently failed. }\end{array}$ \\
\hline$\checkmark \checkmark$ & $\checkmark$ & $x$ & $\checkmark$ & $\begin{array}{l}\text { (8d) The traditional approach has ignored the realities of } \\
\text { history and material development, and thus/therefore it has } \\
\text { consistently failed. }\end{array}$ \\
\hline$\checkmark \checkmark$ & $\checkmark$ & $x$ & $\checkmark$ & $\begin{array}{l}\text { (8e) The traditional approach has ignored ... development, } \\
\text { thus consistently failing. }\end{array}$ \\
\hline
\end{tabular}

complex prepositions, Rohdenburg (1996), cited in Hoffmann 2005, 102) notes that "the more explicit variant is generally represented by the bulkier element or construction", for a simple preposition such as on is "far more general in meaning than upon and can be used in a great variety of concrete and abstract contexts".

In the other two clause simplexes, (3) and (4), the cause relation is marked by lexical markers, i.e. the Process caused in (3) and the Participant cause in (4). Because (2), (3) and (4) are all marked by lexical or semi-lexical Relators, they could be considered equally explicit. All are therefore more explicit than (1).

Table 4 Cohesive sequences

\begin{tabular}{|c|c|c|c|c|}
\hline $\begin{array}{l}\text { Experiential } \\
\text { congruency }\end{array}$ & $\begin{array}{l}\text { Logical } \\
\text { congruency }\end{array}$ & $\begin{array}{l}\text { Textual } \\
\text { congruency }\end{array}$ & Delicacy & Cohesive sequence \\
\hline$\checkmark \checkmark$ & $x$ & $x$ & $x$ & $\begin{array}{l}\text { (9) The traditional approach ignores the realities of history } \\
\text { and material development. It has consistently failed. }\end{array}$ \\
\hline$\checkmark \checkmark$ & $\checkmark$ & $\checkmark$ & $\checkmark$ & $\begin{array}{l}\text { (10) The traditional approach ignores the realities of history } \\
\text { and material development. Therefore, it has consistently } \\
\text { failed. }\end{array}$ \\
\hline$\checkmark \checkmark$ & $\checkmark$ & $\checkmark$ & $\checkmark$ & $\begin{array}{l}\text { (11a) The traditional approach ignores the realities of } \\
\text { history and material development. The result of this was } \\
\text { that it has consistently failed. }\end{array}$ \\
\hline$\checkmark x$ & $\checkmark$ & $\checkmark$ & $\checkmark$ & $\begin{array}{l}\text { (11b) The traditional approach ignores the realities of } \\
\text { history and material development. The result of this was its } \\
\text { consistent failure. }\end{array}$ \\
\hline
\end{tabular}




\section{Set 2: clause complexes}

The clause complexes in Set 2, presented in Table 3 (except for (8b; see below), are all experientially congruent, as they all construe a sequence of figures in clause complexes. Yet, they are not equally explicit just because they are all clause complexes; nor are they all more explicit than the clause simplexes in examples (1)-(4). In fact, examples (5) and (6) can be regarded as implicit as (1), since only one parameter of explicitness is assessed as 'present' in each case. Although example (5) is a clause complex, it is considered logically incongruent because the hypotactic relation is realised by a non-finite clause with no explicit logical cause Relator (see He et al. 2015). Example (6), although it has a logical Relator (and), can also be considered logically incongruent because the function of Relator is realised by what I refer to as a vague structural conjunction (i.e. and), and therefore the intended type of relation will have to be inferred. ${ }^{2}$ It can thus be placed at the same level of explicitness as (5). Examples (5) and (6) illustrate the fact that we cannot then generalise that a clause complex is always more explicit than its agnate simplex.

The remaining clause complexes are all more explicit than the clause simplexes (1)-(4) and clause complexes (5)-(6). The reason is that they all have explicit cause Relators (unlike (5) and (6), in addition to being experientially congruent (unlike (1)-(4). However, we can still differentiate between them if we consider them from the perspective of delicacy. Examples (7a)-(7c) are less explicit than (8a)-(8e), based on delicacy. The cause Relators in (7) are structural, while those in (8) are closer to the lexical end of the cline of delicacy as they indicate their semantic meaning explicitly. Consider the non-finite resulting or the hypotactic binder with the result that. The example with because, which is also a structural Relator, was nevertheless added to group 8 because it still has traces of the lexical meaning and is more specific in meaning than the other structural Relators (since, as, for, and so), which can be used in a variety of functions. Examples (8d) and (8e) were added to this group because the Relator thus/therefore is used within the clause complex rather than in a cohesive sequence. In other words, the conjunctive makes up for the vague conjunction in (8d) and for the missing Relator in (8e). Note that in example (8b) the latter clause nexus is experientially incongruent, which could render (8b) less explicit than examples (8a) and (8c)-(8e). However, in order to avoid complications, such instances could be considered experientially congruent.

\section{Set 3: cohesive sequences}

The examples in Set 3 (Table 4) are all cohesive sequences. As mentioned above a cohesive sequence comprises two figures, or stretches of discourse, that are either tied textually (by a textual conjunctive, e.g. therefore, thus, hence, as a result), or juxtaposed, without a conjunctive. Example (9) is an instance of juxtaposed clauses. In such constructions, it could be difficult to tell whether there is a relation and what type of logico-semantic relation that is (Halliday 1994, 327). From this perspective, example (9) in this set can be regarded as manifesting neither textual nor logical congruence, nor delicacy, and thus as implicit as examples (1), (5), and (6).

\footnotetext{
${ }^{2}$ The term vague relator in this paper stands for any marker that is mainly used to denote functions other than cause or whose meaning is not so specific as to signal cause explicitly, e.g. and.
} 
In example (10), the clauses are linked by the cohesive conjunctive therefore. As mentioned above, conjunctives differ from conjunctions in that they are non-structural and therefore closer to the lexical end of the cline of delicacy. Also, while conjunctions only indicate the logical relationship between clauses, conjunctives realise logical relations in the semantics, in addition to their function as discourse organisers. Therefore, cohesive sequences with explicit conjunctives, as in example (10), are more explicit than the clause simplexes in the first set and all the clause complexes exemplified in the second set.

Examples (11a) and (11b) display the same level of explicitness as (10). In such cohesive sequences, the enhancing clause starts out with a conjunctive expression that signals, with explicit lexical terms, the relation of the following clause or stretch of discourse with the foregoing discourse (e.g. this is the reason, the result of this, etc.). These are referred to as complex conjunctives in this paper. Such instances are dealt with under cohesive sequences since they operate across clauses. When used within the clause, the relevant category is the clause simplex, as exemplified in the first set, i.e. encoding cause in the Process or a Participant. Note that examples (11a) and (11b) could be differentiated in terms of explicitness in that example (11b), similarly to (8b) is partially experientially incongruent. However, as also noted above, this distinction could be ignored to avoid further complications.

The examples in the three sets demonstrate that explicitness does not always increase in line with a move up the rank scale, e.g. from group to clause to clause complex, or from the experiential to the logical to the cohesive. In short, the main determinants of explicitness in manifestations of cause-effect are realisational congruency and delicacy of the Relator, where the former includes experiential congruency, logical congruency, and textual congruency. The following points summarise the procedures adopted for comparing different cause realisations in terms of explicitness.

- In comparing instances of the same rank (e.g. two clause simplexes, two clause complexes, or two cohesive sequences), delicacy is used to measure the degree of explicitness. This is because realisational congruency is a constant within each rank: when construing two figures, a clause simplex is experientially incongruent; whereas a clause complex is experientially congruent, as is a cohesive sequence.

- When comparing a clause simplex with a clause complex or a cohesive sequence, the parameters of congruency and delicacy both need to be considered. As illustrated in the examples above, a clause simplex with a lexical marker of cause (e.g. the verb caused, a noun such as reason, or a complex preposition like as a result of) is more explicit than a clause complex with a non-finite hypotactic clause, as in example (5) above, or with a vague conjunction such as and, as in example (6). Similarly, a clause simplex with a lexical cause marker is more explicit than a cohesive sequence consisting of juxtaposed clauses.

- When comparing clause complexes with cohesive sequences in cases where they both satisfy the two conditions of congruency and delicacy of the Relator, the degree of explicitness is differentiated by looking at the functions of the Relators. Since the function of conjunctions is to construe the logico-semantic relation, while conjunctives also function as discourse organisers, cohesive sequences are more explicit. 


\section{Final remarks: expanding the model}

The cline of explicitness proposed above is intended for a micro-level analysis of individual cause-effect constructions. For a macro-level investigation, a quantitative analysis of such constructions in a certain text can provide us with an idea of its level of explicitness with respect to cause construal. However, since choices made by language users take account of their suitability in particular social contexts, it is very important to consider the text in terms of register, i.e. "varieties of language operating in different contexts of use" (Halliday 1978). In other words, a macro-level analysis could show whether the relevant investigated instances are consistent with established patterns of instantiation in the relevant register. In such an analysis, cause constructions are to be examined collectively or in categories, rather than individually, against registerial conventions or preferences. This will require a quantitative analysis, ideally based on corpus-based investigations. Such an investigation into authentic texts could give a clear picture of how the respective register manifests a division of labour between or among different linguistic features. This macro-level analysis compares the frequencies of text's features, which are obtained from the previous analysis, against a corpus of comparable texts. The eventual objective is to determine how the relevant instances affect the text's level of explicitness as compared to similar texts.

\section{Acknowledgements}

Anonymous reviewers.

\section{Authors' contributions}

Single author. The author(s) read and approved the final manuscript.

Funding

No funding was received.

Availability of data and materials

Not applicable.

\section{Competing interests}

The author declares that he has no competing interests.

Received: 31 July 2019 Accepted: 15 April 2020

Published online: 12 May 2020

\section{References}

Bordet, Lucile, and Denis Jamet. 2010. Are English prepositions lexical or grammatical morphemes? 1-26. Occasional Papers: Cercles www.cercles.com/occasional/ops2010/bordetjamet.pdf.

Bulman, R.J. 1977. "Causality: Psychological and philosophical aspects." PhD diss. Evanston: Northwestern University.

DeLorenzo, Yousef. 1993. Crisis in the Muslim mind. Virginia: International Islamic Publishing House.

Halliday, Michael. 1971. Linguistic function and literary style: An inquiry into the language of William Golding's the inheritors. In Literary style: A symposium, ed. Seymour Chatman, 330-368. New York: Oxford University Press.

Halliday, Michael. 1978. Language as social semiotic: The social interpretation of language and meaning. London: Edward Arnold.

Halliday, Michael. 1992. Language theory and translation practice. Rivista internazionale di tecnica della traduzione 0: 15-25 https://www.openstarts.units.it/handle/10077/8905.

Halliday, Michael. 1994. An introduction to functional grammar. London: Arnold.

Halliday, Michael, and Christian Matthiessen. 1999. Construing experience through meaning: A language-based approach to cognition. London/New York: Cassell.

Halliday, Michael, and Christian Matthiessen. 2004. An introduction to functional grammar. London: Routledge.

Halliday, Michael, and Christian Matthiessen. 2014. Halliday's introduction to functional grammar. 4th ed. Milton Park, Abingdon, Oxon: Routledge.

Hasan, Ruqaiya. 1984. Ways of saying: Ways of meaning. In The semiotics of culture and language: Language as social semiotic, ed. Robin P. Fawcett et al., 105-162. London: Printer.

He, Qingshun, Bingjun Yang, and Binli Wen. 2015. Textual metaphor from the perspective of relator. Australian Journal of Linguistics 35 (4): 334-350. https://doi.org/10.1080/07268602.2015.1067134.

Hoffmann, Sebastian. 2005. Grammaticalization and English complex prepositions: A corpus-based study. London and New York: Routledge.

Martin, James. 1992. English text: System and structure. Amsterdam: John Benjamins. 
Matthiessen, Christian, Kasuhiro Teruya, and Marvin Lam. 2010. Key terms in systemic functional linguistics. London and New York: Continuum.

Neeleman, Ad, and Hans Van de Koot. 2012. The linguistic expression of causation. In The Theta System: Argument Structure at the Interface, ed. Martin Everaert, Marijana Marelj, and Tal Siloni, 20-51. Oxford: Oxford University Press.

Quinton, Anthony. 1977. Causality. In The Fontana Dictionary of Modern Thought, ed. Alan Bullock and Oliver Stallybrass, 9192. London: Fontana Books.

Rohdenburg, Günter. 1996. Cognitive complexity and increased grammatical explicitness in English. Cognitive Linguistics 7 (2): 149-182. https://doi.org/10.1515/cogl.1996.7.2.149.

Teich, Elke. 2003. Crosslinguistic variation in system and text: A methodology for the investigation of translations and comparable texts. Berlin: Mouton de Gruyter.

Thompson, Geof. 1996. Introducing functional grammar. London: Edward Arnold.

Thompson, Geof, and Peter Muntigl. 2008. Systemic functional linguistics: An interpersonal perspective. In Handbook of interpersonal communication, ed. Gerd Antos and Eija Ventola, 107-132. Berlin and New York: Mouton de Gruyter.

\section{Publisher's Note}

Springer Nature remains neutral with regard to jurisdictional claims in published maps and institutional affiliations.

Submit your manuscript to a SpringerOpen ${ }^{\circ}$ journal and benefit from:

- Convenient online submission

- Rigorous peer review

- Open access: articles freely available online

- High visibility within the field

- Retaining the copyright to your article

Submit your next manuscript at $\boldsymbol{\nabla}$ springeropen.com 